ARTICLE OPEN

\title{
Changes in initial COPD treatment choice over time and factors influencing prescribing decisions in UK primary care: a real-world study
}

\author{
Kevin Gruffydd-Jones ${ }^{1}$, Guy Brusselle ${ }^{2,3}$, Rupert Jones ${ }^{4}$, Marc Miravitlles ${ }^{5}$, Michael Baldwin ${ }^{6}$, Rebecca Stewart ${ }^{7}$, Anna Rigazio $^{7}$, \\ Emily Davis ${ }^{7}$, Dorothy L Keininger ${ }^{8}$ and David Price ${ }^{7,9}$
}

Prescribing patterns in chronic obstructive pulmonary disease (COPD) are often inconsistent with published guidelines. This retrospective, observational study utilised data from the Optimum Patient Care Research Database to examine the changes in COPD prescribing patterns over time and to identify predictors of physician treatment choice for patients newly diagnosed with COPD. Initial therapy was defined as the treatment(s) prescribed at or within 1 year before COPD diagnosis. Changes over time were assessed in three cohorts based on the date of diagnosis: (1) 1997-2001; (2) 2002-2006; and (3) 2007-2010. Factors affecting the odds of being prescribed any initial therapy or any initial maintenance therapy were identified by univariable and multivariable logistic regression. The analysis included 20,154 patients, $45 \%$ of whom were prescribed an initial regimen containing an inhaled corticosteroid (ICS), whereas $28 \%$ received no initial pharmacological treatment. Prescribing of ICS monotherapy decreased over time, as did the proportion of patients receiving no therapy at or within 1 year before diagnosis. Comorbid asthma, a high exacerbation rate, increased symptoms and poor lung function each increased the likelihood of being prescribed any initial therapy or initial maintenance therapy; comorbid asthma and an annual rate of $\geqslant 3$ exacerbations were the strongest predictors. In conclusion, our analyses revealed major differences between actual prescribing behaviour and guideline recommendations for patients with newly diagnosed COPD, with many patients receiving no treatment and large numbers of patients receiving ICS-containing regimens. Predictors of initial therapy were identified.

npj Primary Care Respiratory Medicine (2016) 26, 16002; doi:10.1038/npjpcrm.2016.2; published online 25 February 2016

\section{INTRODUCTION}

Chronic obstructive pulmonary disease (COPD) places a high burden on the healthcare system and society in the UK. ${ }^{1}$ An effective way to minimise the burden of any disease is through appropriate care, including pharmacological management. In the UK, most COPD care is provided in primary care. ${ }^{2}$ However, recommendations in national and international guidelines are based on evidence obtained in randomised clinical trials, ${ }^{3}$ which recruit patients mainly from secondary or tertiary care. Patients enrolled into randomised clinical trials differ from those seen in primary care in that they may be younger, take fewer concomitant medications and have more severe airflow limitation, worse quality of life, fewer comorbidities, a more significant smoking history and a clearer diagnosis of COPD. ${ }^{4-7}$ Thus, although primary care treatment decisions should be based on the guidelines, adaptation of management strategies to reflect the characteristics of patients seen in primary care is warranted. ${ }^{3}$

The UK National Institute for Health and Care Excellence (NICE) guidelines for COPD were introduced in 2004 and updated partially in $2010^{8,9}$ They recommend a multidimensional approach to the assessment of COPD severity, taking into account the degree of airflow obstruction and factors such as disability and exacerbation frequency. ${ }^{8-10}$ In the 2004 guidelines, therapy recommendations focused on treating symptoms, with shortand long-acting bronchodilators recommended for symptomatic patients, and inhaled corticosteroid (ICS) reserved only for frequent exacerbators with a forced expiratory volume $\left(\mathrm{FEV}_{1}\right)$ $\leqslant 50 \%$ predicted. ${ }^{8}$ In the updated (2010) guidelines, the treatment focus shifted to the prevention of future risk, with treatment choice being determined by the level of post-bronchodilator $\mathrm{FEV}_{1} \cdot{ }^{9,10}$

In contrast to the 2004 NICE guidelines, the 2003 Global initiative for chronic Obstructive Lung Disease (GOLD) recommendations assessed disease severity solely on the basis of airflow limitation. ${ }^{11}$ They recommended the initial use of bronchodilators to treat symptoms and ICS as an add-on therapy in patients with $\mathrm{FEV}_{1}<50 \%$ predicted and frequent exacerbations (e.g., three in the last 3 years). The updated GOLD strategy recommends that COPD is assessed according to current symptoms and future risk, based on lung function and exacerbation frequency. ${ }^{12}$ Currently, the use of ICS (in combination with bronchodilators) is recommended only for patients at high risk of exacerbations $\left(\geqslant 2\right.$ exacerbations per year, or $\geqslant 1$ leading to hospital admission). ${ }^{12}$

Prescribing patterns for COPD are often not in accordance with guidelines. Previous studies, including one from our group, ${ }^{13}$ have shown a higher use of ICS and under-prescription of

\footnotetext{
${ }^{1}$ Box Surgery, Corsham, UK; ${ }^{2}$ Department of Respiratory Medicine, Ghent University Hospital, Ghent, Belgium; ${ }^{3}$ Erasmus Medical Center, Department of Epidemiology and Respiratory Medicine, Rotterdam, The Netherlands; ${ }^{4}$ Centre for Clinical Trials and Population Research, Plymouth University Peninsula Schools of Medicine and Dentistry, Plymouth, UK; ${ }^{5}$ Department of Pneumology, Hospital Universitari Vall d'Hebron, Ciber de Enfermedades Respiratorias (CIBERES), Barcelona, Spain; ${ }^{6}$ Novartis Pharmaceuticals, Horsham, UK; ${ }^{7}$ Research in Real Life, Cambridge, UK; ${ }^{8}$ Novartis Pharma AG, Basel, Switzerland and ${ }^{9}$ Centre of Academic Primary Care, University of Aberdeen, Aberdeen, UK. Correspondence: D Price (dprice@rirl.org)
}

Received 16 October 2015; revised 30 November 2015; accepted 2 December 2015 
bronchodilators than expected based on the guidelines. Many patients do not receive any treatment despite experiencing symptoms, whereas others receive treatment without due regard to severity of airflow limitation, asthma diagnosis or exacerbation history, and without appropriate spirometric assessment. ${ }^{13-21}$ These findings highlight some important issues regarding the treatment of patients in primary care. To understand why these prescribing patterns occur, an assessment of the predictors of physician prescribing behaviour, an area currently unexplored in the literature, is required.

The aims of this retrospective, observational study were to examine the changes in COPD prescribing patterns over time and to identify predictors of physician treatment choice for patients newly diagnosed with COPD.

\section{RESULTS}

Patients

Of 42,704 patients registered in the study period, 20,154 met the eligibility criteria and were included in the analysis (Supplementary Figure S1). The median age of patients across all cohorts was 66 years (Table 1). The proportions of men and women were similar (52 and $48 \%$, respectively). The majority of patients were ex-smokers (49\%) or current smokers (46\%); $4.4 \%$ of patients were classified as non-smokers, and there were also three patients with unknown smoking status. Patient baseline characteristics per cohort are presented in Supplementary Table S1; the prevalence of specific comorbidities in the overall study population is shown in Supplementary Table S2.

\section{COPD initial treatment patterns}

Analysis of initial therapy in the overall study population showed that $45 \%$ of patients were prescribed ICS, either alone or in combination with a long-acting $\beta_{2}$-agonist (LABA) and/or longacting muscarinic antagonist (LAMA); Figure 1. More than one in four patients $(28 \%)$ did not receive any prescription.

Analysis of initial therapy according to year of COPD diagnosis showed that ICS monotherapy prescriptions decreased from the 1997-2001 cohort to the 2002-2006 and 2007-2010 cohorts, whereas ICS/LABA prescriptions and triple therapy (ICS/LABA/ LAMA) increased progressively over time (Figure 2). There were no prescriptions for LAMAs in the 1997-2001 cohort, because LAMA therapy was not available in the UK until 2002. ${ }^{22}$ The proportion of patients receiving no therapy at or within 1 year before COPD diagnosis decreased progressively over time, from 33 to $26 \%$ (Figure 2).

\section{Predictors of initial COPD treatment}

Results from the univariable analysis to identify factors predicting any initial therapy and initial maintenance therapy are presented in Supplementary Table S3. Multivariable analysis of patients receiving their first therapy during the year before or at the date of COPD diagnosis (subset of patients with modified Medical Research Council (mMRC) data available $(n=16,185))$ showed that patients with an annual rate of $\geqslant 3$ exacerbations had 4.6 times higher odds of receiving any initial COPD therapy and 3.8 times higher odds of receiving initial maintenance therapy than patients with no exacerbations. Patients with comorbid asthma had 3.9 and 5.5 times higher odds of receiving any/initial maintenance therapy, respectively, than patients without comorbid asthma. Lung function grade and $\mathrm{mMRC}$ score were weaker predictors of therapy choice (Tables 2 and 3).

In an analysis of the subgroup of patients who received their first therapy on the date of COPD diagnosis, mMRC score or an annual exacerbation rate of $\geqslant 3$ (versus 0 ) were not found to be predictors of any/initial maintenance therapy. Having a lung
Table 1. Patient baseline characteristics and demographics (overall population)

\begin{tabular}{|c|c|}
\hline Characteristics & $\mathrm{N}=20,154$ \\
\hline Age, years, median (IQR) & $66(59-73)$ \\
\hline Gender, male, $n$ (\%) & $10,509(52)$ \\
\hline Body mass index, $\mathrm{kg} / \mathrm{m}^{2}$, median (IQR) & $26.5(23-30)$ \\
\hline \multicolumn{2}{|l|}{ Smoking status, $n$ (\%) } \\
\hline Non-smoker & $893(4.4)$ \\
\hline Smoker & $9,304(46)$ \\
\hline Ex-smoker & $9,954(49)$ \\
\hline Comorbid asthma (at any time), $n(\%)$ & $4,056(20)$ \\
\hline \multicolumn{2}{|c|}{$\begin{array}{l}\text { Exacerbation rate during the year before and including the initial date of } \\
\text { COPD diagnosis, } \mathrm{n}(\%)\end{array}$} \\
\hline 0 & $12,147(60)$ \\
\hline 1 & $4,819(24)$ \\
\hline 2 & $1,700(8.4)$ \\
\hline$\geqslant 3$ & $1,488(7.4)$ \\
\hline \multicolumn{2}{|l|}{ Lung function, $\mathrm{n}$ (\%) } \\
\hline Grade 1 (mild: FEV $_{1} \geqslant 80 \%$ predicted) & $3,012(15)$ \\
\hline Grade 2 (moderate: $50 \% \leqslant \mathrm{FEV}_{1}<80 \%$ predicted) & $11,077(55)$ \\
\hline Grade 3 (severe: $30 \% \leqslant \mathrm{FEV}_{1}<50 \%$ predicted) & $5,090(25)$ \\
\hline Grade 4 (very severe: $\mathrm{FEV}_{1}<30 \%$ predicted) & $975(4.8)$ \\
\hline \multicolumn{2}{|l|}{ mMRC score, $\mathrm{n}(\%)$} \\
\hline Unknown & $3,969(20)$ \\
\hline $0-1$ & $9,371(46)$ \\
\hline $2+$ & $6,814(34)$ \\
\hline \multicolumn{2}{|c|}{$\begin{array}{l}\text { Abbreviations: COPD, chronic obstructive pulmonary disease; } \mathrm{FEV}_{1} \text {, forced } \\
\text { expiratory volume in } 1 \mathrm{~s} \text {; IQR, interquartile range; mMRC, modified Medical } \\
\text { Research Council. }\end{array}$} \\
\hline
\end{tabular}

function Grade of 3 or 4 (versus Grade 2) did not significantly affect the odds of receiving initial therapy, but patients with lung function Grade 3 or 4 were more likely to receive initial maintenance therapy than patients with lung function Grade 2 (odds ratio 1.2 and 1.6, respectively). Patients with comorbid asthma were less likely to be prescribed initial therapy than patients without comorbid asthma (odds ratio 0.8); comorbid asthma was not a predictor of maintenance treatment in this patient subgroup (Tables 2 and 3).

\section{DISCUSSION}

Main findings

Our analyses showed that $28 \%$ of patients did not receive any pharmacological therapy at or within 1 year before COPD diagnosis, which is surprising given the high levels of symptoms and poor lung function in our study population. However, the proportion of patients receiving no therapy decreased over time, perhaps because of increased awareness among physicians (e.g., with the introduction of the Quality and Outcomes Framework (QOF) in the UK in $2004,{ }^{23}$ and GOLD and NICE treatment guidelines/recommendations in $2001^{24}$ and $2004^{8}$ respectively) and improved data recording. ${ }^{25}$ In the total study population, a diagnosis of comorbid asthma and a higher rate of exacerbations were strongly predictive of an increased likelihood of receiving any initial treatment, whereas lung function and mMRC score were weaker predictors.

In our study, relatively few patients received LABAs or LAMAs as monotherapy. Although such treatments are now recommended as first-line options for many patients, ${ }^{9,12}$ only LABA monotherapy would have been available in the earliest cohorts because the first LAMA was licensed in the UK in 2002.22 Monotherapy as first-line treatment increased in the later cohorts but remained low 
All patients $(n=20,154)$ Patients with $\geqslant 1$ prescription $(n=14,607)$

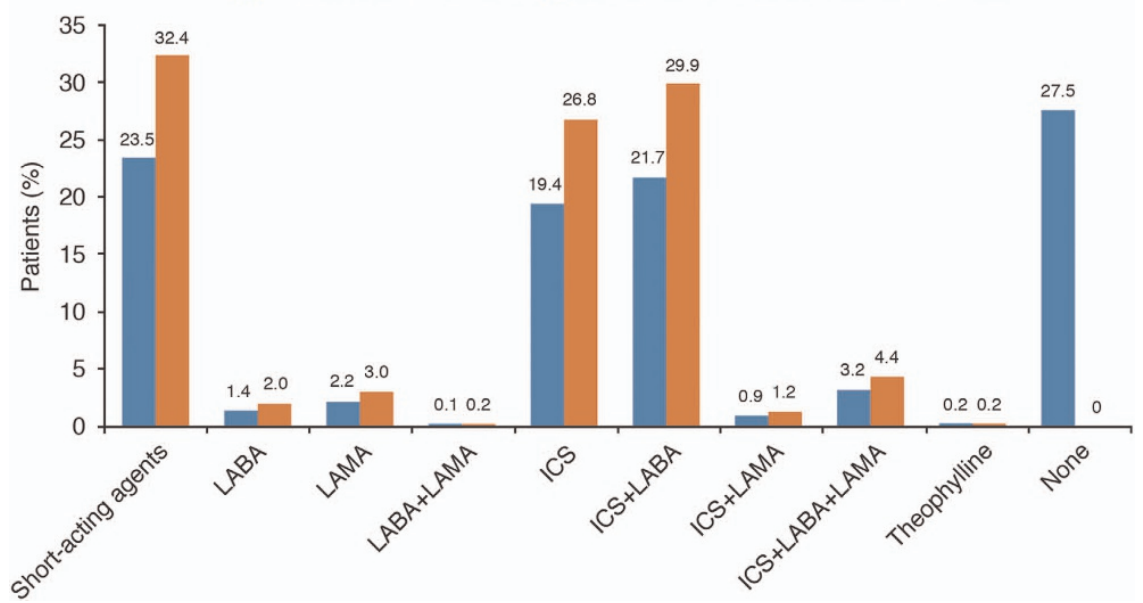

Figure 1. Initial pharmacological therapy (overall population). ICS, inhaled corticosteroid; LABA, long-acting $\beta_{2}$-agonist; LAMA, long-acting muscarinic antagonist.

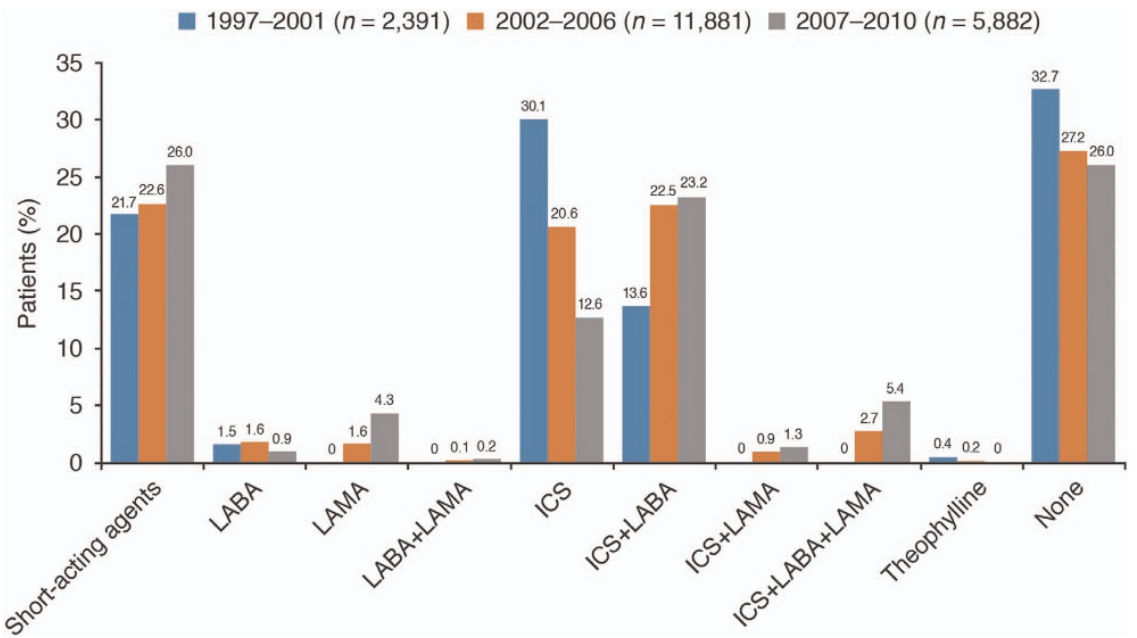

Figure 2. Initial pharmacological therapy according to year of COPD diagnosis. ICS, inhaled corticosteroid; LABA, long-acting $\beta_{2}$-agonist; LAMA, long-acting muscarinic antagonist.

compared with the use of LABA+ICS. The use of ICS monotherapy decreased over time; however, $13 \%$ of patients were still prescribed such treatment in the 2007-2010 cohort. The prescribing of ICS-containing regimens remained similar between 1997 and 2001, and 2007 and 2010, with an increased use of ICS combination therapies compensating for the reduction in the use of ICS monotherapy.

There were notable differences in the treatment predictors identified in the total study population (patients treated up to 1 year before diagnosis) and the subgroup that received their first treatment at diagnosis. Comorbid asthma was a predictor of initial maintenance treatment before diagnosis, but not at diagnosis. One explanation could be that comorbid asthma, whether correctly or incorrectly diagnosed, drives maintenance treatment decisions before a formal COPD diagnosis, but once COPD is diagnosed in its own right it drives treatment decisions by itself. Furthermore, mMRC score was predictive of treatment before diagnosis but not at diagnosis. One explanation could be that the GOLD strategy at the time recommended treatment based on lung function and not on symptoms. ${ }^{11}$ At diagnosis, lung function would, therefore, have been the main consideration when determining therapy.
Interpretation of findings in relation to previously published work Consistent with previous studies, ${ }^{13,17,26-28}$ our study showed high prescribing rates of ICS/LABA in patients with COPD. Similarly, a disconnect between real-world prescription patterns and national guidelines or GOLD treatment recommendations has been documented in other countries. ${ }^{18,19,21,28,29}$ The novelty of our study compared with these earlier descriptive studies was in analysing the drivers of treatment decisions in primary care.

Strengths and limitations of the study

This was a large study of real-life data, highlighting differences between COPD guidelines and real-world prescribing patterns in the UK. The length of the study and its historical nature give a unique insight into prescribing patterns and drivers of primary care treatment decisions before, during and after the introduction of major UK and international guidelines that are still in place today.

Potential study limitations include the fact that the data set reflects UK opinions, attitudes and drug availability, and analyses in other countries are needed before these findings can be extrapolated more widely. Although the gap between real-world prescription patterns and guidelines is evident in our findings, 
Table 2. Factors predictive of any initial therapy: multivariable analysis (reduced best-fitting model)

\begin{tabular}{|c|c|c|c|c|}
\hline & \multirow[t]{2}{*}{ Patients ( $\mathrm{n}$ ) } & \multicolumn{3}{|c|}{$\begin{array}{c}\text { Odds of being prescribed any initial therapy } \\
\text { versus no therapy }\end{array}$} \\
\hline & & $O R^{\mathrm{a}}(95 \% \mathrm{Cl})$ & $\mathrm{P}$ value & Overall $\mathrm{P}$ value ${ }^{\mathrm{b}}$ \\
\hline \multicolumn{5}{|c|}{$\begin{array}{l}\text { All patients, including those treated at or up to } 1 \text { year before COPD } \\
\text { diagnosis }^{\mathrm{c}}\end{array}$} \\
\hline \multicolumn{5}{|c|}{ Comorbid asthma diagnosis (reference category: no; $(n=12,922))$} \\
\hline Yes & 3,263 & $3.88(3.43,4.40)$ & $<0.001$ & $<0.001$ \\
\hline \multicolumn{5}{|c|}{ Lung function grade (reference category: $2 ;(n=8,964)$ ) } \\
\hline 1 & 2,274 & $0.87(0.78,0.97)$ & 0.009 & 0.001 \\
\hline 3 & 4,163 & $1.10(1.01,1.20)$ & 0.038 & \\
\hline 4 & 784 & $1.13(0.95,1.36)$ & 0.174 & \\
\hline \multicolumn{5}{|c|}{ mMRC score (reference category: $0 ;(n=2,234)$ ) } \\
\hline 1 & 7,137 & $1.17(1.05,1.31)$ & 0.005 & $<0.001$ \\
\hline 2 & 4,003 & $1.22(1.08,1.38)$ & 0.001 & \\
\hline 3 & 2,232 & $1.26(1.10,1.46)$ & 0.001 & \\
\hline 4 & 579 & $1.40(1.12,1.75)$ & 0.003 & \\
\hline \multicolumn{5}{|c|}{ Annual exacerbation rate (reference category: $0 ;(n=9,708)$ ) } \\
\hline 1 & 3,857 & $2.33(2.12,2.56)$ & $<0.001$ & $<0.001$ \\
\hline 2 & 1,405 & $3.60(3.03,4.27)$ & $<0.001$ & \\
\hline$\geqslant 3$ & 1,215 & $4.62(3.75,5.69)$ & $<0.001$ & \\
\hline \multirow{2}{*}{\multicolumn{5}{|c|}{$\begin{array}{l}\text { Subgroup of patients, excluding those treated before COPD diagnosis }{ }^{\mathrm{d}} \\
\text { Comorbid asthma diagnosis (reference category: no; }(n=7,229) \text { ) }\end{array}$}} \\
\hline & & & & \\
\hline Yes & 550 & $0.80(0.65,0.98)$ & 0.028 & 0.028 \\
\hline \multicolumn{5}{|c|}{ Lung function grade (reference category: $2 ;(n=4,336)$ ) } \\
\hline 1 & 1,201 & $0.79(0.68,0.92)$ & 0.002 & 0.007 \\
\hline 3 & 1,870 & $1.01(0.90,1.14)$ & 0.835 & \\
\hline 4 & 372 & $1.13(0.89,1.44)$ & 0.303 & \\
\hline \multicolumn{5}{|c|}{ Annual exacerbation rate (reference category: $0 ;(n=5,827))$} \\
\hline 1 & 1,432 & $1.74(1.54,1.97)$ & $<0.001$ & $<0.001$ \\
\hline 2 & 338 & $1.78(1.41,2.23)$ & $<0.001$ & \\
\hline$\geqslant 3$ & 182 & $1.34(0.97,1.84)$ & 0.072 & \\
\hline \multicolumn{5}{|c|}{ mMRC score (reference category: $0 ;(n=921))^{\mathrm{e}}$} \\
\hline 1 & 2,671 & - & - & NS \\
\hline 2 & 1,506 & - & - & \\
\hline 3 & 796 & - & - & \\
\hline 4 & 202 & - & - & \\
\hline \multicolumn{5}{|c|}{ 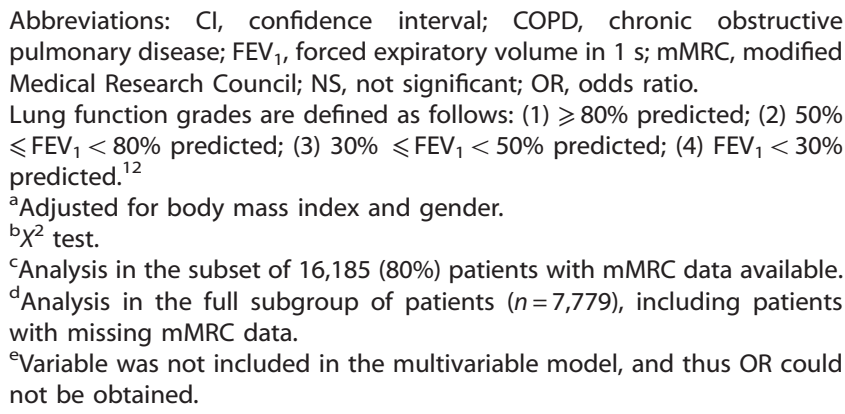 } \\
\hline
\end{tabular}

factors contributing to this and the strength of their correlation need to be substantiated. Another limitation is that data recording in this study may have been incomplete. For example, prescriptions or exacerbations during Emergency Department visits may have not been recorded properly; in earlier cohorts, an initial asthma diagnosis may have later changed into one of COPD without the asthma code being terminated, and prescriptions in the earlier cohorts would have been handwritten and may have been lost or damaged.

A further limitation is that some patients who appeared to have received unnecessary ICS prescriptions may have had comorbid asthma that was not recorded (between 2004 and 2006, the QOF definitions prevented patients from being in both the asthma and COPD registers; patients with COPD and comorbid asthma would, therefore, have been missed). ${ }^{30}$ Thus, these results should be
Table 3. Factors predictive of initial maintenance therapy prescription (long-acting agents; ICS with/without long-acting agents; theophylline): multivariable analysis (reduced best-fitting model)

\begin{tabular}{|c|c|c|c|c|}
\hline & \multirow[t]{2}{*}{ Patients ( $\mathrm{n}$ ) } & \multicolumn{3}{|c|}{$\begin{array}{l}\text { Odds of being prescribed initial maintenance } \\
\text { therapy versus short-acting or no therapy at all }\end{array}$} \\
\hline & & $O R^{\mathrm{a}}(95 \% C l)$ & $\mathrm{P}$ value & Overall $\mathrm{P}$ value $\mathrm{b}^{\mathrm{b}}$ \\
\hline \multicolumn{5}{|c|}{$\begin{array}{l}\text { All patients, including those treated at or up to } 1 \text { year before COPD } \\
\text { diagnosisc }\end{array}$} \\
\hline \multicolumn{5}{|c|}{ Comorbid asthma diagnosis (reference category: no; $(n=12,922)$ ) } \\
\hline Yes & 3,263 & $5.47(4.97,6.02)$ & $<0.001$ & $<0.001$ \\
\hline \multicolumn{5}{|c|}{ Lung function grade (reference category: $2 ;(n=8,964)$ ) } \\
\hline 1 & 2,274 & $0.96(0.87,1.06)$ & 0.434 & $<0.001$ \\
\hline 3 & 4,163 & $1.18(1.09,1.28)$ & $<0.001$ & \\
\hline 4 & 784 & $1.39(1.18,1.63)$ & $<0.001$ & \\
\hline \multicolumn{5}{|c|}{ mMRC score (reference category: $0 ;(n=2,234))$} \\
\hline 1 & 7,137 & $1.17(1.06,1.30)$ & 0.003 & $<0.001$ \\
\hline 2 & 4,003 & $1.29(1.15,1.44)$ & $<0.001$ & \\
\hline 3 & 2,232 & $1.31(1.15,1.49)$ & $<0.001$ & \\
\hline 4 & 579 & $1.67(1.37,2.04)$ & $<0.001$ & \\
\hline \multicolumn{5}{|c|}{ Annual exacerbation rate (reference category: $0 ;(n=9,708)$ ) } \\
\hline 1 & 3,857 & $1.62(1.49,1.75)$ & $<0.001$ & $<0.001$ \\
\hline 2 & 1,405 & $2.54(2.24,2.87)$ & $<0.001$ & \\
\hline$\geqslant 3$ & 1,215 & $3.78(3.27,4.38)$ & $<0.001$ & \\
\hline \multirow{2}{*}{\multicolumn{5}{|c|}{$\begin{array}{l}\text { Subgroup of patients, excluding those treated before COPD diagnosis } \\
\text { Lung function grade (reference category: } 2 ;(n=4,336))\end{array}$}} \\
\hline & & & & \\
\hline 1 & 1,201 & $0.88(0.70,1.10)$ & 0.255 & 0.001 \\
\hline 3 & 1,870 & $1.22(1.03,1.46)$ & 0.023 & \\
\hline 4 & 372 & $1.63(1.20,2.21)$ & 0.002 & \\
\hline \multicolumn{5}{|c|}{ Annual exacerbation rate (reference category: 0 ; $(n=5,827)$ ) } \\
\hline 1 & 1,432 & $1.50(1.26,1.79)$ & $<0.001$ & $<0.001$ \\
\hline 2 & 338 & $1.80(1.32,2.45)$ & $<0.001$ & \\
\hline$\geqslant 3$ & 182 & $1.30(0.82,2.07)$ & 0.264 & \\
\hline \multicolumn{5}{|c|}{ Comorbid asthma diagnosis (reference category: no; $(n=7,229))^{\mathrm{e}}$} \\
\hline & 550 & & - & NS \\
\hline \multicolumn{5}{|c|}{ mMRC score (reference category: $0 ;(n=921))^{\mathrm{e}}$} \\
\hline 1 & 2,671 & - & - & NS \\
\hline 2 & 1,506 & - & - & \\
\hline 3 & 796 & - & - & \\
\hline 4 & 202 & - & - & \\
\hline
\end{tabular}

Abbreviations: $\mathrm{Cl}$, confidence interval; COPD, chronic obstructive pulmonary disease; $\mathrm{FEV}_{1}$, forced expiratory volume in $1 \mathrm{~s}$; ICS, inhaled corticosteroid; mMRC, modified Medical Research Council; NS, not significant; $\mathrm{OR}$, odds ratio.

Lung function grades are defined as follows: (1) $\geqslant 80 \%$ predicted; (2) $50 \%$ $\leqslant \mathrm{FEV}_{1}<80 \%$ predicted; (3) $30 \% \leqslant \mathrm{FEV}_{1}<50 \%$ predicted; (4) $\mathrm{FEV}_{1}<30 \%$ predicted. ${ }^{12}$

${ }^{\mathrm{a}}$ Adjusted for body mass index and gender.

${ }^{b} X^{2}$ test.

'Analysis in the subset of $16,185(80 \%)$ patients with mMRC data available. ${ }^{\mathrm{d}}$ Analysis in the full subgroup of patients $(n=7,779)$, including patients with missing mMRC data.

'Variable was not included in the multivariable model, and thus OR could not be obtained.

interpreted with caution. Notably, the 2014 GOLD and Global Initiative for Asthma Global Strategy for Asthma Management and Prevention reports now highlight asthma-COPD overlap syndrome as an important factor to consider in managing patients with COPD. ${ }^{12,31}$

This study also compares prescribing patterns from an era that predates the GOLD A-D classification. Data reported by GOLD A-D here are, therefore, illustrative of habits, but they were not part of the framework used by physicians at that time.

Finally, this study only considers data from primary care practice, and any therapies prescribed by pulmonologists will not have been included. This might explain some of the patients who did not have any recorded prescription in this study $(28 \%$ in 
total). However, it should be noted that in the UK the vast majority of prescriptions are written in primary care; prescriptions are written by specialists only in emergencies. Therefore, the effect of this on our results is expected to be minimal.

Implications for future research, policy and practice

The results from this study raise several interesting questions for future research. One question that arises from this study is whether or not any of the other comorbidities identified in this population (e.g., cardiovascular disease; depression/anxiety; diabetes) are predictors of doctors' prescribing habits (such as comorbid asthma has been shown to be). These analyses were outside the remit of our study, but they would be important areas to explore further in future research. Similarly, one could explore the potential effect of socio-economic variables, such as differences in educational level across the population, on treatment choices. In addition, it would be valuable to further characterise the large proportion of patients who had received no treatment $(28 \%)$.

Traditionally, COPD has been considered as more prevalent in men than in women. However, evidence suggests that the prevalence of COPD is increasing in women, even in populations in which the overall prevalence may be decreasing. ${ }^{32}$ A recent WHO report states that COPD now affects men and women almost equally. ${ }^{33}$ Although our model was adjusted for gender, the effect of gender on treatment choice would be an interesting research topic to consider.

There is a pressing need to change healthcare professionals' behaviour so they understand that adherence to COPD guidelines has the potential to improve treatment outcomes for large numbers of patients, by reducing inappropriate exposure to ICS and its associated risks (e.g., pneumonia), ${ }^{34}$ as well as to reduce the societal burden of the disease. The reasons why treatment and prescriptions do not comply with guideline recommendations remain unclear and were outside the remit of this study. More research is needed to elucidate this further; however, one likely possibility is that physicians simply react to the patients in front of them, and their treatment decisions may be guided more by clinical events rather than by guideline recommendations. Indeed, GOLD now recognises clinical events, such as exacerbations, to be as important as lung function when making decisions on initial therapy. ${ }^{12}$ However, the need to treat any patient with symptoms or exacerbations is clear. Non-compliance with guidelines may also be related to failure to make a diagnosis or to treat according to a diagnosis, or insufficient/inaccurate knowledge of the disease process or the guidelines. Finally, it may be that the habit of prescribing ICS starts with asthma (appropriately) and passes on to prescriptions for COPD, despite differences in the licensed indications for the two conditions. Although changing physicians' prescribing habits is not an easy task, tools and support services could be implemented to facilitate the correct use of guidelines. Suggestions include more frequent audits, reviews (such as the clinical support services provided by Optimum Patient Care $^{35}$ ), availability of prescribing advisors or templates in primary care with feedback on management steps according to guidelines and provision of more educational materials.

This study was conducted before approval of the LABA/LAMA fixed-dose combinations that are now available for the treatment of COPD (once-daily indacaterol/glycopyrronium 110/50 $\mu \mathrm{g}$ and vilanterol/umeclidinium 25/62.5 $\mu \mathrm{g}$ were approved in the EU and the US, respectively, in 2013). ${ }^{36,37}$ Therefore, the use of these therapies was close to zero throughout the study. These dual bronchodilator treatments are now central to COPD management, being an alternative treatment choice to LABA or LAMA monotherapy in GOLD Group B patients (high-symptom burden; low-exacerbation risk) and an alternative to LABA/ICS combination therapy in GOLD Group C or D patients (severe airflow limitation, or high risk of COPD exacerbations). ${ }^{12}$ It will be interesting to investigate what effect the approval of these newer therapies will have on COPD prescribing patterns in the coming years, particularly in relation to the use of ICS/LABA combinations.

\section{Conclusions}

In the UK, many patients who received a diagnosis of COPD did not receive any pharmacological treatment despite symptoms and exacerbations. ICS-containing regimens were widely used irrespective of exacerbations, and patients were prescribed ICS monotherapy in the absence of comorbid asthma, which was not recommended by any COPD guidelines. The percentage of patients who did not receive treatment and the percentage of patients prescribed ICS monotherapy decreased in the later cohorts. The use of ICS combination therapies, including ICS $+\mathrm{LABA}, \mathrm{ICS}+\mathrm{LAMA}$ and ICS+LABA+LAMA, all increased in the later cohorts. Comorbid asthma, high exacerbation rate, increased symptoms and poor lung function were identified as drivers of prescription of initial and maintenance therapy.

\section{MATERIALS AND METHODS}

Data source

The Optimum Patient Care Research Database (OPCRD), ${ }^{38}$ which at the time of data extraction comprised anonymised data from 318 UK practices, was used. ${ }^{39}$ The OPCRD is a quality-controlled, longitudinal, primary care respiratory database that combines routinely recorded clinical data from electronic patient records with patient-reported data collected using disease-specific questionnaires. The clinical data extracted from primary care management systems include lung function data, patient demographics, diseases typically comorbid with COPD, exacerbation history, mMRC score and therapy history.

The OPCRD has been approved by the Trent Multicentre Research Ethics Committee for clinical research use. The independent Anonymized Data Ethics Protocols and Transparency committee verified and approved the planned analysis. ${ }^{39}$

This study is registered at www.clinicaltrials.gov (NCT01786720).

\section{Patient population}

The patients included were newly diagnosed with COPD, $\geqslant 40$ years of age at the date of diagnosis, which was based on the QOF-approved Read Code (Supplementary Methods), with spirometry data supportive of a COPD diagnosis (post-bronchodilator $\mathrm{FEV}_{1} /$ forced vital capacity $<0.7$ ) recorded in the 5-year window around the date of diagnosis. The data used in these analyses were from the years 1997 to 2013. To examine changes in treatment patterns over time, patients were split into three cohorts based on the date of diagnosis: (1) 1997-2001; (2) 2002-2006; and (3) 2007-2010. Cohorts were chosen to assess the impact of the first GOLD report publication (2001), UK approval of tiotropium (2002) and introduction of the QOF (2004). ${ }^{22,24,40}$

COPD initial therapy was defined as pharmacological therapy prescribed during the year before and at the date of COPD diagnosis. There was no minimum number of prescriptions required to mark the initiation of pharmacological treatment. COPD therapies were grouped by treatment class. To identify possible drivers of treatment choice, analyses were conducted in subgroups according to year of diagnosis; the presence of comorbid asthma (based on physician-recorded Read Codes for asthma); lung function grade; mMRC dyspnoea scale score; and baseline exacerbation rate (at or within 1 year before COPD diagnosis).

\section{Clinical variables}

Lung function grades and mMRC scores recorded closest to the date of COPD diagnosis were used in this analysis. Lung function grade was determined using GOLD Stage 1, 2, 3 and 4 criteria, ${ }_{12}^{2}$ and mMRC scores were based on the 5-point scale of the British Medical Research Council questionnaire assessing perceived breathlessness ${ }^{12}$ (see Supplementary Information for further details).

Exacerbation rates were calculated during the year before and including the date of COPD diagnosis. Data were obtained from medical records. Exacerbations were defined as any one or more of the following: 
(i) COPD-related hospital admissions or Emergency Department attendance; (ii) the use of acute oral corticosteroids; and/or (iii) general practitioner consultations for lower respiratory tract infections. Two exacerbations occurring within 2 weeks of one another were counted only once.

\section{Statistical analysis}

Summary statistics were generated for all baseline variables. COPD therapies prescribed before and at the date of COPD diagnosis were quantified as a complete data set. Factors significantly $(P<0.05)$ affecting (i) the odds of being prescribed any initial COPD therapy versus no therapy and (ii) the odds of receiving initial maintenance therapy versus shortacting agents or no therapy were identified with univariable logistic regression. These were included in a multivariable logistic regression model with stepwise reduction to derive a best-fitting model of noncollinear (Spearman's co-efficient $\leqslant 0.3$ ) predictors. The models were adjusted for body mass index and gender, as these variables were found to be significant predictors of treatment. Analyses were conducted within the total population of patients receiving first therapy (based on prescribing during the year before and at the date of COPD diagnosis) and in the subgroup of patients who received their first therapy on the date of COPD diagnosis. Potential predictors studied were as follows: year of COPD diagnosis, comorbid asthma, lung function, mMRC score, annual exacerbation rates and GOLD Group ( $B$ versus $A, D$ versus $C$ and $C+D$ versus $A+B)$. Multivariable analyses for the total study population were undertaken on the subset of patients with mMRC data available.

\section{ACKNOWLEDGEMENTS}

Samantha Holmes (CircleScience, an Ashfield Company, part of UDG Healthcare plc) and Paul Hutchin (contracted to CircleScience, an Ashfield Company, part of UDG Healthcare plc) provided medical writing assistance.

\section{CONTRIBUTIONS}

$K G-J, R J, M M, M B, R S, A R, E D$ and DP contributed to the plan and design of the study. KG-J, RS, AR and DP contributed to data analysis. KG-J, GB, RJ, MM, MB, RS, ED, DLK and DP contributed to data interpretation. All the authors were involved in drafting of the manuscript, commented on draft versions, and read and approved the final manuscript. DP is a guarantor of this work.

\section{COMPETING INTERESTS}

KG-J has acted as a consultant for, and spoken on behalf of, Almirall, AstraZeneca, Boehringer Ingelheim, Chiesi, GlaxoSmithKline, Mundipharma/Napp, Novartis and Teva. GB has received honoraria for lectures from AstraZeneca, Boehringer Ingelheim, Chiesi, GlaxoSmithKline, MSD, Novartis, Pfizer and UCB; he is a member of advisory boards for AstraZeneca, Boehringer Ingelheim, GlaxoSmithKline and Novartis. RJ has received personal fees from Almirall, AstraZeneca, Boehringer Ingelheim, Chiesi, GlaxoSmithKline, Health Intelligence; grants, personal fees and non-financial support from Novartis; and personal fees and non-financial support from Mundipharma/ Napp. MM has received speaker fees from Almirall, AstraZeneca, Boehringer Ingelheim, Chiesi, Esteve, GlaxoSmithKline, Grifols, Menarini, Novartis and Pfizer, and consulting fees from Almirall, Boehringer Ingelheim, CSL Behring, Gebro Pharma, GlaxoSmithKline, Grifols, Medlmmune, Novartis and Pfizer. MB was an employee of Novartis at study initiation. Currently, he is an employee of Boehringer Ingelheim GmbH (Germany). RS, AR and ED are employees of Research in Real-Life, which has conducted paid research in respiratory disease on behalf of the following organisations: Aerocrine, AKL Ltd, Almirall, Boehringer Ingelheim, Chiesi, GlaxoSmithKline, Meda, Mundipharma, Napp, Novartis, Orion, Takeda, Teva and Zentiva. DLK is an employee of Novartis Pharma AG (Basel, Switzerland). DP discloses the following. Advisory board membership: Aerocrine, Almirall, Amgen, AstraZeneca, Boehringer Ingelheim, Chiesi, Meda, Mundipharma, Napp, Novartis and Teva. Consultancy: Almirall, Amgen, AstraZeneca, Boehringer Ingelheim, Chiesi, GlaxoSmithKline, Meda, Mundipharma, Napp, Novartis, Pfizer and Teva. Grants/ grants pending: Aerocrine, AstraZeneca, Boehringer Ingelheim, British Lung Foundation, Chiesi, Eli Lilly, GlaxoSmithKline, Meda, Merck, Mundipharma, Novartis, Orion, Pfizer, Respiratory Effectiveness Group, Takeda, Teva, UK National Health Service and Zentiva. Payments for lectures/speaking: Almirall, AstraZeneca, Boehringer Ingelheim, Chiesi, Cipla, GlaxoSmithKline, Kyorin, Meda, Merck, Mundipharma, Novartis, Pfizer, SkyePharma, Takeda and Teva. Payment for manuscript preparation: Mundipharma and Teva. Patents (planned, pending or issued): AKL Ltd. Payment for the development of educational materials:
GlaxoSmithKline and Novartis. Stock/stock options: shares in AKL Ltd, which produces phytopharmaceuticals, and owns $80 \%$ of Research in Real Life Ltd and its subsidiary social enterprise Optimum Patient Care. Payment for travel/accomodation/ meeting expenses: Aerocrine, Boehringer Ingelheim, Mundipharma, Napp, Novartis and Teva. Funding for patient enrolment or completion of research: Almirall, Chiesi, Teva and Zentiva. Peer reviewer for grant committees: Efficacy and Mechanism Evaluation programme (2012), HTA (2014) and Medical Research Council (2014). Unrestricted funding for investigator-initiated studies: Aerocrine, AKL Ltd, Almirall, Boehringer Ingelheim, Chiesi, Meda, Mundipharma, Napp, Novartis, Orion, Takeda, Teva and Zentiva.

\section{FUNDING}

The study was funded by Novartis Pharma AG (Basel, Switzerland).

\section{REFERENCES}

1. Britton M. The burden of COPD in the U.K.: results from the Confronting COPD survey. Respir. Med. 2003; 97 (Suppl C): S71-S79.

2. Upton, J. et al. What provokes experienced COPD clinical practitioners in the UK to initiate or change medication? A consensus study. Prim. Care Respir. J. 20, 155-160, 152 (2011)

3. Roche, N. et al. Integrating real-life studies in the global therapeutic research framework. Lancet Respir. Med. 1, e29-e30 (2013).

4. Kruis, A. L. et al. Primary care COPD patients compared with large pharmaceutically-sponsored COPD studies: an UNLOCK validation study. PLOS ONE 9, e90145 (2014).

5. Travers, J. et al. External validity of randomized controlled trials in COPD. Respir. Med. 101, 1313-1320 (2007).

6. Martin, K. et al. Differences between clinical trials and postmarketing use. Br. J. Clin. Pharmacol. 57, 86-92 (2004).

7. Herland, K., Akselsen, J. P., Skjønsberg, O. H. \& Bjermer, L. How representative are clinical study patients with asthma or COPD for a larger 'real life' population of patients with obstructive lung disease? Respir. Med. 99, 11-19 (2005).

8. National Institute for Health and Care Excellence (NICE). Chronic obstructive pulmonary disease. Management of chronic obstructive pulmonary disease in adults in primary and secondary care. NICE clinical guideline 101. February 2004. Last accessed on 13 January 2015. Available at http://www.nice.org.uk/guidance/ cg12.

9. National Institute for Health and Care Excellence (NICE). Chronic obstructive pulmonary disease. Management of chronic obstructive pulmonary disease in adults in primary and secondary care. NICE clinical guideline 101 (partial update). Updated June 2010. Last accessed on 7 August 2015. Available at https://www.nice.org.uk/guidance/cg101/resources/guidance-chronic-obstructivepulmonary-disease-pdf.

10. Gruffydd-Jones, K. \& Loveridge, C. The 2010 NICE COPD Guidelines: how do they compare with the GOLD guidelines? Prim. Care Respir. J. 20, 199-204 (2011).

11. Global initiative for chronic Obstructive Lung Disease (GOLD). Global strategy for the diagnosis, management, and prevention of chronic obstructive pulmonary disease. Updated 2003. Last accessed on 14 January 2015. Available at http://www.goldcopd.org/Guidelines/guidelines-global-strategy-for-diagnosismanagement-2003-clean.html.

12. Global initiative for chronic Obstructive Lung Disease (GOLD). Global strategy for the diagnosis, management, and prevention of chronic obstructive pulmonary disease. Updated 2015. Last accessed on 17 November 2015. Available at http:// www.goldcopd.org/uploads/users/files/GOLD_Report_2015.pdf.

13. Price, D. et al. Management of COPD in the UK primary-care setting: an analysis of real-life prescribing patterns. Int. J. Chron. Obstruct. Pulmon. Dis. 9, 889-905 (2014).

14. Roche, N., Lepage, T., Bourcereau, J. \& Terrioux, P. Guidelines versus clinical practice in the treatment of chronic obstructive pulmonary disease. Eur. Respir. J. 18, 903-908 (2001).

15. Katz, P. M. \& Pegoraro, V. L'utilizzo dei corticosteroidi nei pazienti con la broncopneumopatia cronica ostruttiva: aspetti epidemiologici ed economici. Farmecon. Percorsi Ter. 10, 139-148 (2009).

16. Jochmann, A. et al. Impact of adherence to the GOLD guidelines on symptom prevalence, lung function decline and exacerbation rate in the Swiss COPD cohort. Swiss Med. Wkly 142, W13567 (2012).

17. Drivenes, E., Ostrem, A. \& Melbye, H. Predictors of ICS/LABA prescribing in COPD patients: a study from general practice. BMC Fam. Pract. 15, 42 (2014).

18. Miravitlles, M. et al. Use of spirometry and patterns of prescribing in COPD in primary care. Respir. Med. 101, 1753-1760 (2007).

19. Bourbeau, J. et al. Practice patterns in the management of chronic obstructive pulmonary disease in primary practice: the CAGE study. Can. Respir. J. 15, 13-19 (2008). 
20. Jones, R. C., Dickson-Spillmann, M., Mather, M. J., Marks, D. \& Shackell, B. S. Accuracy of diagnostic registers and management of chronic obstructive pulmonary disease: the Devon primary care audit. Respir. Res. 9, 62 (2008).

21. Roche, N. et al. Real-life use of fluticasone propionate/salmeterol in patients with chronic obstructive pulmonary disease: a French observational study. BMC Pulm. Med. 14, 56 (2014).

22. Yohannes, A. M., Connolly, M. J. \& Hanania, N. A. Ten years of tiotropium: clinica impact and patient perspectives. Int. J. Chron. Obstruct. Pulmon. Dis. 8 117-125 (2013)

23. Roland, M. Linking physicians' pay to the quality of care-a major experiment in the United Kingdom. N. Engl. J. Med. 351, 1448-1454 (2004).

24. Global initiative for chronic Obstructive Lung Disease (GOLD). Global strategy for the diagnosis, management, and prevention of chronic obstructive pulmonary disease. Updated 2001. Last accessed on 13 January 2015. Available at http://www.goldcopd.org/Guidelines/guidelines-global-strategy-for-diagnosismanagement-2001.html.

25. Gillam, S. J., Siriwardena, A. N. \& Steel, N. Pay-for-performance in the United Kingdom: impact of the quality and outcomes framework: a systematic review. Ann. Fam. Med. 10, 461-468 (2012).

26. Hurst, J. R. et al. Susceptibility to exacerbation in chronic obstructive pulmonary disease. N. Engl. J. Med. 363, 1128-1138 (2010).

27. Miravitlles, M. et al. Geographic differences in clinical characteristics and management of COPD: the EPOCA study. Int. J. Chron. Obstruct. Pulmon. Dis. 3, 803-814 (2008)

28. Jochmann, A. et al. General practitioners' adherence to the COPD GOLD guidelines:baseline data from the Swiss COPD Cohort Study. Swiss Med. Wkly 140, W13053 (2010).

29. Decramer, M., Bartsch, P., Pauwels, R. \& Yernault, J. C. Management of COPD according to guidelines. A national survey among Belgian physicians. Monaldi Arch. Chest Dis. 59, 62-80 (2003).

30. Scotland, I. Information for users of QOF register and prevalence data. Last accessed on 16 January 2015. Available at http://www.isdscotland.org/HealthTopics/General-Practice/Quality-And-Outcomes-Framework/Information-for-usersof-QOF-register-and-prevalence-data.asp.

31. Global Initiative for Asthma (GINA). Diagnosis of diseases of chronic airflow limitation: Asthma COPD and asthma-COPD Overlap Syndrome (ACOS).
Updated May 2014. Last accessed 30 June 2014. Available at http://www. ginasthma.org/local/uploads/files/AsthmaCOPDOverlap.pdf.

32. Bischoff, E. W. et al. Trends in COPD prevalence and exacerbation rates in Dutch primary care. Br. J. Gen. Pract. 59, 927-933 (2009).

33. World Health Organization (WHO). Chronic obstructive pulmonary disease (COPD). Updated 2015. Last accessed on 20 July 2015. Available at http://www. who.int/mediacentre/factsheets/fs315/en/.

34. Suissa, S., Patenaude, V., Lapi, F. \& Ernst, P. Inhaled corticosteroids in COPD and the risk of serious pneumonia. Thorax 68, 1029-1036 (2013).

35. Optimum Patient Care. Clinical reviews. Updated 2015. Last accessed on 20 July 2015. Available at http://optimumpatientcare.org/services-provided/clinicalreviews/.

36. Electronic Medicines Compendium (EMC). Ultibro Breezhaler. SmPC. Updated January 2015. Last accessed on 8 October 2015. Available at https://www.med cines.org.uk/emc/medicine/29533.

37. GlaxoSmithKline (GSK). Anoro Ellipta prescribing information. Revised May 2014. Last accessed on 18 November 2015. Available at https://www.gsksource. com/pharma/content/dam/GlaxoSmithKline/US/en/Prescribing_Information/Anoro_ Ellipta/pdf/ANORO-ELLIPTA-PI-MG.PDF.

38. Optimum Patient Care. Optimum Patient Care Research Database (OPCRD). 2014. Last accessed on 17 August 2015. Available at http://www.optimumpatientcare. org/OPCRD.html.

39. Optimum Patient Care. Optimum Patient Care Research Database (OPCRD). 2014. Last accessed on 30 June 2014. Available at http://www.optimumpatientcare.org/ Html_Docs/OPCRD.html.

40. Health \& Social Care Information Centre (HSIC). Quality and Outcomes Framework. Updated October 2014. Last accessed 14 January 2015. Available at http://www.hscic.gov.uk/qof.

c) (i) $\Theta$ This work is licensed under a Creative Commons AttributionNonCommercial-NoDerivatives 4.0 International License. The images or other third party material in this article are included in the article's Creative Commons license, unless indicated otherwise in the credit line; if the material is not included under the Creative Commons license, users will need to obtain permission from the license holder to reproduce the material. To view a copy of this license, visit http:// creativecommons.org/licenses/by-nc-nd/4.0/

Supplementary Information accompanies the paper on the npj Primary Care Respiratory Medicine website (http://www.nature.com/npjpcrm). 
ERRATUM OPEN

\section{Changes in initial COPD treatment choice over time and factors influencing prescribing decisions in UK primary care: a real-world study}

Kevin Gruffydd-Jones, Guy Brusselle, Rupert Jones, Marc Miravitlles, Michael Baldwin, Rebecca Stewart, Anna Rigazio, Emily Davis, Dorothy L Keininger and David Price

npj Primary Care Respiratory Medicine (2017) 27, 17004; doi:10.1038/npjpcrm.2017.4; published online 8 June 2017

Correction to: npj Primary Care Respiratory Medicine (2016) 26, 16002. doi:10.1038/npjpcrm.2016.2; published online 25 February 2016

An error was introduced in the title of this paper at typesetting.

'Changes in initial COPD treatment choice over time and factors influencing prescribing decisions in UK primary care: in UK primary care: a real-world, retrospective, observational'

Should have been 'Changes in initial COPD treatment choice over time and factors influencing prescribing decisions in UK primary care: a real-world study'
An Erratum has been published and is appended to both the HTML and PDF versions of this paper. The error has been fixed in the paper.

(c) (i) $\odot$ This work is licensed under a Creative Commons Attributioncc) NonCommercial-NoDerivatives 4.0 International License. The images or other third party material in this article are included in the article's Creative Commons license, unless indicated otherwise in the credit line; if the material is not included under the Creative Commons license, users will need to obtain permission from the license holder to reproduce the material. To view a copy of this license, visit http:// creativecommons.org/licenses/by-nc-nd/4.0/

(c) The Author(s) 2017 